\title{
Prediction of Optimum Weld Tensile Strength Using Response Surface Methodology
}

\author{
L. M. Ebhota and C. E. Etin-Osa
}

\begin{abstract}
Metals are often subjected to various types of stresses, usually under tensile stress, quick failure of material can be encouraged especially when poor combinations of process parameters are employed in joining of the material. Tensile strength is regarded as the maximum stress that a material can sustain under tension. The aim of this study is to predict the weld tensile strength of tungsten inert gas (TIG) mild steel welds using Response Surface Methodology (RSM), with the purpose of achieving optimum results.

The input parameters considered were current, voltage, and gas flow rate. The TIG welding process was used to join two pieces of mild steel plates, after which tensile test was conducted on the specimen. The experimental result was analyzed using the RSM.

Weld Tensile test of 596.218MPa with a desirability value of $95.70 \%$ was observed to be the best, resulting from the optimized process parameters of current of $120.00 \mathrm{Amp}$, voltage of 20.00 volt and gas flow rate of $12.00 \mathrm{~L} / \mathrm{min}$.
\end{abstract}

Index Terms - Mild Steel, RSM, surface Plot, Tensile test, TIG.

\section{INTRODUCTION}

The importance of mild steel in our daily activity cannot be over emphasized. Usually, this materials are subjected to different form of stresses and in other to prevent sudden failure, it is imperative to determine the strength of the material through subjecting it to various forms of test [1]. According to [2], the failure of structural materials especially steel is of great concern globally. Some material properties affected due to welding includes tensile strength, hardness, macro and micro-structural features and toughness [3]. Tensile strength described as the maximum stress that a material can sustain under tension. In other words, it can be defined as the amount of applied load per cross sectional area that a material can withstand before failure. Mathematically it is calculated as the ratio of maximum tensile load to the original cross section area. Mild steel or low carbon steel offers numerous applications in fields of construction and engineering. The carbon in steel affects the material's ductility and strength; steel with higher percentage of carbon are stronger compared to low carbon steel [4]. On the other hand, high carbon steel are less ductile when compared to low carbon steel. Mild steel is the most versatile and common form of steel as it provide mechanical properties that are acceptable for many applications [5]. No doubt that mild steel has become an indispensable class for different applications

Submitted on April 05, 2021

Published on April 28, 2021.

L. M. Ebhota, Groove Engineering \&Intergrated services Limited, Nigeria. (e-mail: grooveengineeringservices@gmail.com) like construction of large ships; oil, water and gas pipelines; drilling platforms; pressure vessels; building constructions; bridges; storage tanks etc. Welding on the other hand is a joining process of two or more metals [6]. This process usually introduce large amount of heat into the welded zone, thereby altering the microstructure around the area of the welded material [7]. If not properly controlled, it could reduce the tensile strength around the welded vicinity and alter the factor of safety initially designed for. Tungsten inert gas (TIG) welding is one of the best arc welding processes currently in used. This research work was aimed at prediction and optimization of tensile strength of mild steel specimen with the use of response surface methodology (RSM) tool.

\section{MATERIALS AND Methods}

\section{A. Materials}

Mild steel plate of $10 \mathrm{~mm}$ and $100 \%$ argon gas were purchased locally and transferred to the Department of Welding and fabrication technology, Petroleum Training Institute (PTI), Warri, Delta State, Nigeria. The $10 \mathrm{~mm}$ plate was cut into 200 pieces of dimension $140 \mathrm{~mm}$ by $30 \mathrm{~mm}$ by $10 \mathrm{~mm}$ with a power hacksaw and welded. After welding, the specimens were trimmed with an angle grinder to take a dog bone shape, so it could fit into the tensometer. Response surface methodology (RSM) was employed to analyze the results obtained. The input ranges of parameters used for the research is presented in Table I.

TABLE I: WELDING PROCESS PARAMETERS LIMITS

\begin{tabular}{ccccc}
\hline $\begin{array}{c}\text { Process } \\
\text { parameters }\end{array}$ & Unit & Symbol & Low (-) & High (+) \\
\hline Welding & Amp & I & 120 & 170 \\
$\begin{array}{c}\text { Current } \\
\text { Welding }\end{array}$ & Volts & V & 20 & 25 \\
$\begin{array}{c}\text { Voltage } \\
\text { Gas Flow Rate }\end{array}$ & Lit/mill & F & 12 & 14 \\
\hline
\end{tabular}

The selected input parameters have the upper $(+)$ and lower limits (-). The limits of the four welding variables are shown in Table I.

\section{B. Method}

After welding, the sample was reduced to 100 pieces, prepared with the following dimensions as presented in Fig. 1. $\mathrm{l}_{2}=280 \mathrm{~mm}, \mathrm{~b}_{1}=30 \mathrm{~mm}, 10=80 \mathrm{~mm}, \mathrm{~b}=15 \mathrm{~mm} \mathrm{l}=100$ $\mathrm{mm}$ and $\mathrm{t}=10 \mathrm{~mm}$. The experimental process was performed 20 times, with five (5) specimens for each run.

C. E. Etin-Osa, Department of Production Engineering, University of Benin Benin City, Edo State, Nigeria.

(e-mail: etinosa.eruogun ${ }^{@}$ uniben.edu) 


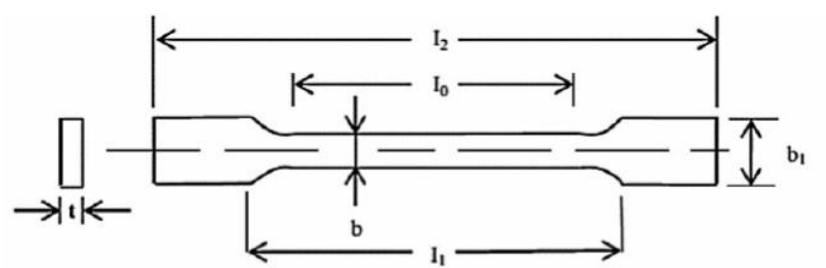

Fig. 1. Measurement of Tensile Test Piece.

\section{RESULTS}

Twenty (20) experimental runs were carried out, each experimental run comprising the weld current, weld voltage and gas flow rate. The tensile strength test, was measured and the responses presented in Table II.

\begin{tabular}{ccccc}
\multicolumn{2}{c}{ TABLE II: EXPERIMENTAL RESUlT FOR THE TENSILE STRENGTH TEST } \\
\hline \multirow{2}{*}{ Run } & $\begin{array}{c}\text { A: Welding } \\
\text { Current }\end{array}$ & $\begin{array}{c}\text { B: Welding } \\
\text { Voltage }\end{array}$ & $\begin{array}{c}\text { C: Gas } \\
\text { Flow Rate }\end{array}$ & $\begin{array}{c}\text { Tensile } \\
\text { Test }\end{array}$ \\
\cline { 2 - 5 } & Amp & Volts & Lit/mill & MPa \\
\hline 1 & 145 & 22.5 & 13 & 508.725 \\
2 & 145 & 22.5 & 13 & 491.4 \\
3 & 187.045 & 22.5 & 13 & 557.7 \\
4 & 145 & 22.5 & 11.3182 & 557.55 \\
5 & 170 & 20 & 12 & 511.15 \\
6 & 145 & 18.2955 & 13 & 497.7 \\
7 & 170 & 25 & 14 & 574.403 \\
8 & 120 & 20 & 14 & 510.3 \\
9 & 170 & 25 & 12 & 526.05 \\
10 & 120 & 25 & 12 & 584.325 \\
11 & 120 & 20 & 12 & 589.05 \\
12 & 102.955 & 22.5 & 13 & 601.65 \\
13 & 170 & 20 & 14 & 474.075 \\
14 & 145 & 22.5 & 14.6818 & 502.425 \\
15 & 145 & 22.5 & 13 & 499.275 \\
16 & 145 & 22.5 & 13 & 530.675 \\
17 & 145 & 26.7045 & 13 & 540.225 \\
18 & 145 & 22.5 & 13 & 516.6 \\
19 & 120 & 25 & 14 & 565.425 \\
20 & 145 & 22.5 & 13 & 474.075 \\
\hline
\end{tabular}

The Analysis of Variance (ANOVA) obtained from Table III with P-value of 0.0004 , shows that the model source for the tensile test is statistically significant. ANOVA is a tool in statistics employed to determine whether there are any significant differences of means among two (2) or more groups. Accuracy of the mathematical model greatly depends on the numbers of individual variables (i.e., A, B, C etc.) in the model with $\mathrm{p}$-values less than 0.05 .

TABLE III: ANOVA FOR TENSILE TEST RESPONSE

\begin{tabular}{ccccccc}
\hline Source & $\begin{array}{c}\text { Sum of } \\
\text { Squares }\end{array}$ & df & $\begin{array}{c}\text { Mean } \\
\text { Square }\end{array}$ & $\begin{array}{c}\text { F- } \\
\text { value }\end{array}$ & $\begin{array}{c}\text { p- } \\
\text { value }\end{array}$ & \\
\hline Model & 25720.46 & 9 & 2857.83 & 11.06 & 0.0004 & significant \\
A-Welding Current & 4124.59 & 1 & 4124.59 & 15.96 & 0.0025 & \\
B-Welding Voltage & 4117.94 & 1 & 4117.94 & 15.93 & 0.0026 & \\
C-Gas Flow Rate & 2348.28 & 1 & 2348.28 & 9.08 & 0.0130 & \\
AB & 525.33 & 1 & 525.33 & 2.03 & 0.1845 & \\
AC & 1483.15 & 1 & 1483.15 & 5.74 & 0.0376 & \\
BC & 2638.19 & 1 & 2638.19 & 10.21 & 0.0096 & \\
A & 9911.53 & 1 & 9911.53 & 38.34 & 0.0001 & \\
B & 326.54 & 1 & 326.54 & 1.26 & 0.2873 & \\
C & 1080.29 & 1 & 1080.29 & 4.18 & 0.0682 & \\
Residual & 2585.08 & 10 & 258.51 & & & \\
Lack of Fit & 617.61 & 5 & 123.52 & 0.3139 & 0.8854 & significant \\
Pure Error & 1967.47 & 5 & 393.49 & & & \\
Cor Total & 28305.55 & 19 & & & & \\
\hline
\end{tabular}

Coefficient of determination (R-Squared) values of 0.9087 as observed in Table 4 which shows the strength of response surface methodology (RSM) and its ability to maximize the weld tesnsile test. Adjusted (R-Squared) values of 0.8265 as observed in Table IV indicates a model with $82.65 \%$ reliability. Adequate Precision measures the signal to noise ratio. A ratio greater than 4 is desirable. Adequate precision values of 10.93 as observed in Table IV indicate an adequate signal. This model can be used to navigate the design space and maximize the weld tensile test (TT).

\begin{tabular}{cccc} 
TABLE IV: Model SUMmaRY STATISTICS FOR TENSILE TEST \\
\hline Std. Dev. & 16.08 & $\mathrm{R}^{2}$ & 0.9087 \\
Mean & 530.64 & Adjusted R & 0.8265 \\
C.V. $\%$ & 3.03 & Predicted R & 0.7297 \\
& & Adeq Precision & 10.9300 \\
\hline
\end{tabular}

The mathmatical model representing the weld tensile test (TT) is presented in (1). A denotes the welding current, b reperent the welding voltage and $\mathrm{C}$ represent the gas flow rate.

$T T=503.57-17.38 A+17.36 B-13.11 C+8.10 A B+$ $13.62 A C+18.16 B C+26.23 A^{2}+4.76 B^{2}+8.66 C^{2}(1)$

To asses the correctness of forecast and established the fitness of response surface methodology using the quadratic model, a reliability plot of the predicted and actualvalues of the weld tensile test response were obtained as presented in Fig. 2.

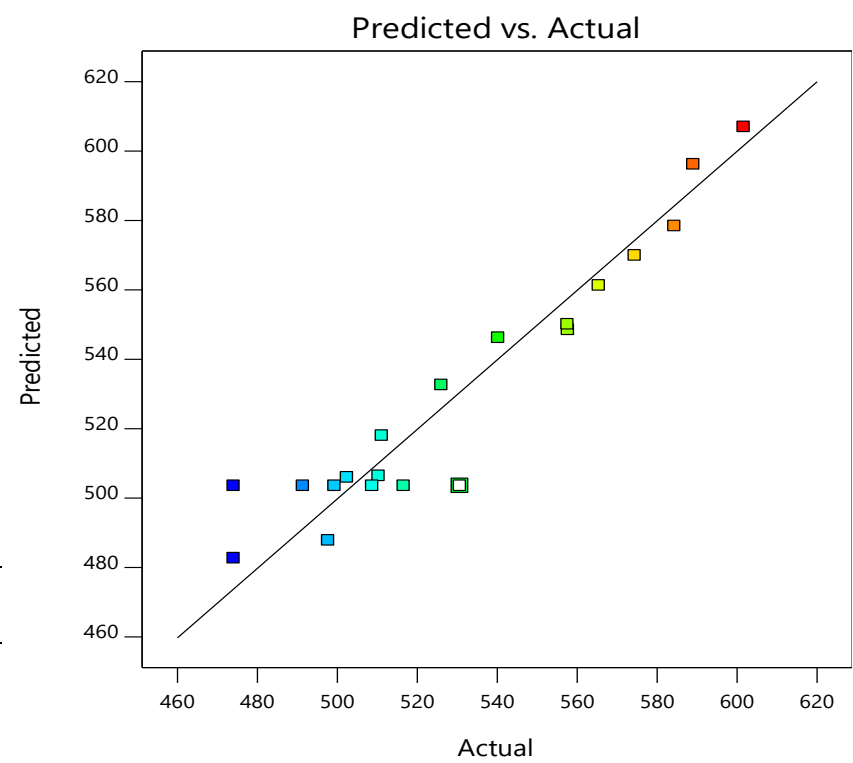

Fig. 2. Reliability plot of predicted versus actual weld tensile test response.

To examine the effects of combine variables such as the weld current and voltage at constant gas flow rate of $13 \mathrm{~L} / \mathrm{min}$, on the weld tensile test, the $3 \mathrm{D}$ surface plots presented in Fig. 3 was employed. 


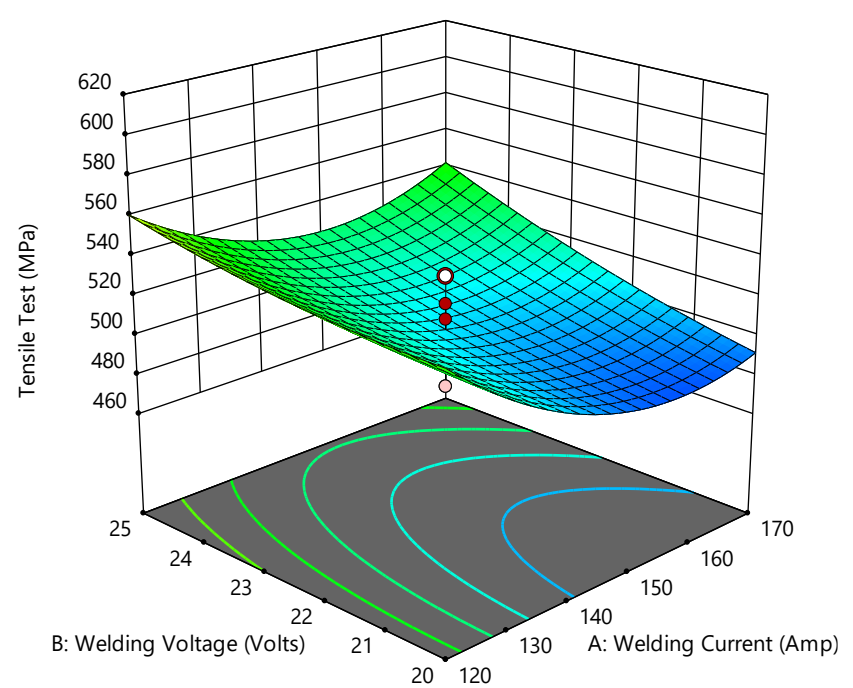

Fig. 3. 3D surface plot showing theEffect of current and voltage on weld tensile test.

Numerical optimization was accomplished to ascertain the attractiveness of the overall model. In the numerical optimization phase, design expert was instructed to maximize the weld tensile test while also determining the optimum value for voltage, current and gas flow rate. Fig. 4 presents the interphase of the numerical optimization with maximization goal target.

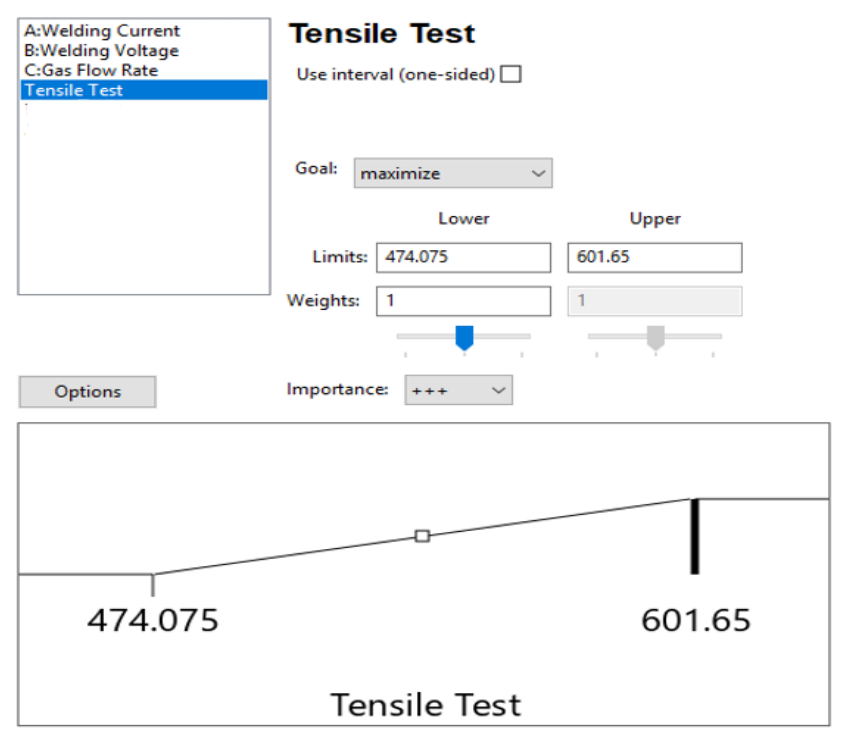

Fig. 4. Interphase of numerical optimization model for maximizing WPSF.

Table V shows the numerical optimization. Eighteen (18) optimal solutions where produced, but five where selected.

TABLE V: FIVE OPTIMUM SOLUTION FOR THE WELD TENSILE TEST

\begin{tabular}{ccccccc}
\hline \multirow{2}{*}{ Number } & $\begin{array}{c}\text { Welding } \\
\text { Current }\end{array}$ & $\begin{array}{c}\text { Welding } \\
\text { Voltage }\end{array}$ & $\begin{array}{c}\text { Gas Flow } \\
\text { Rate }\end{array}$ & $\begin{array}{c}\text { Tensile } \\
\text { Test }\end{array}$ & Desirability & \\
\hline 1 & 120.00 & 20.00 & 12.00 & 596.22 & 0.957 & Selected \\
2 & 120.00 & 20.00 & 12.00 & 596.22 & 0.957 & \\
3 & 120.03 & 20.00 & 12.01 & 595.59 & 0.952 & \\
4 & 120.00 & 20.18 & 12.00 & 594.93 & 0.946 & \\
5 & 120.00 & 20.00 & 12.02 & 594.77 & 0.945 & \\
\hline
\end{tabular}

From the results of Table V, it was observed that current of 120.00 Amp, voltage of 20.00 volt, and gas flow rate of 12.00 $\mathrm{L} / \mathrm{min}$ produced a weld tensile test of $596.218 \mathrm{MPa}$. This solution obtained was selected by design expert as the optimal solution with a desirability value of $95.70 \%$.

Finally, based on the optimal solution obtained, the contour plots showing the weld tensile test response variable against the optimized value of the input variable is presented in Fig. 5 .

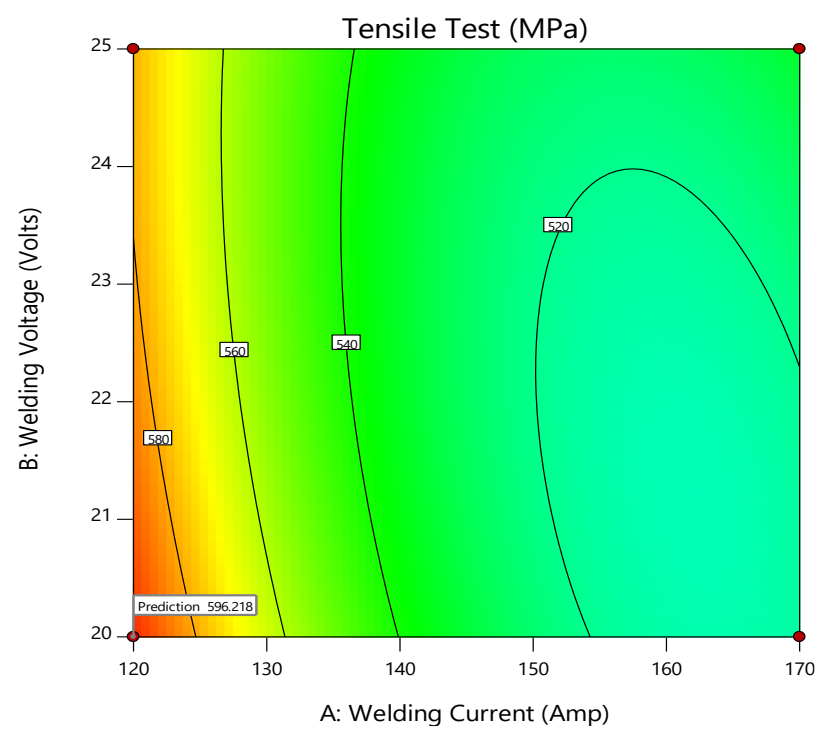

Fig. 5. Predicting weld Tesnsile test using contour plot.

\section{DISCUSSION}

The responses obtained in Table II, was employed to develop the ANOVA table presented in Table III. The Model F-value of 11.06 was obtained which implies the model was significant, as only $0.04 \%$ could result due to noise in the system. The P-values obtained was less than 0.0500 indicating a significant model terms. From Table III, current, voltage and gas flow rate were represented with $\mathrm{A}, \mathrm{B}$ and $\mathrm{C}$ coded symbols. A, B, C, AC, BC and $\mathrm{A}^{2}$ had a p-value less than 0.05 , which implies that the mathematical model formed using these combinations would produce a significant model terms with reduced prediction error. Those values greater than 0.1000 in Table III, are not significant. If there are too many insignificant model terms, it may affect the prediction accuracy of the model. In Table IV, it was observed that the Predicted $\mathbf{R}^{\mathbf{2}}$ of 0.7297 was in reasonable agreement with the Adjusted $\mathbf{R}^{2}$ of 0.8265 ; having a difference of 0.0968 which was less than 0.2 in line with literature. Adequate Precision was used to measures the signal to noise ratio. A ratio greater than 4 was desirable, according to literature. In Table IV, a ratio of 10.930 was obtained, indicating a robust adequate precision. This model was applied to navigate the design space, and (1) was developed to predict the weld tensile test.

In establishing the correctness of the reliability for predicting the weld tensile test, a linear plot was used to fit the predicted and actual response as shown in Fig. 2, the results showed an acceptable positive slope with minimal noise along the slope. From the 3D surface plot provided in Fig. 3, it was also observed that an increase in current, greatly affect the tensile strength. The green area on the 3D mat denotes the area with good tensile strength, while the blue area shows the lowest tensile region. To maximize the tensile strength, process parameters that would result to responses in 
the green zone should be targeted. The interphace of numerical optimization presented in Fig. 4, defines the lower and upper limit of the response with the level of importance indicated. In other to maximize the weld tensile strength, the weight leans towards the higher limit as seen in Fig. 4. The contour plots in Fig. 5 show the predicted optimization region of weld tensile test. The red region represents the area with the strongest tensile test.Just like in Fig. 3, it was also observed that the weld current had a stronger effect on the tensile test. From the results of Table V, it was observed that current of 120.00 Amp, voltage of 20.00 volt, and gas flow rate of $12.00 \mathrm{~L} / \mathrm{min}$ produced an optimal weld tensile test of $596.218 \mathrm{MPa}$ with a desirability value of $95.70 \%$.

\section{CONCLUSION}

In this study,prediction and optimization of weld tensile test was conducted on mild steel welded specimen using tungsten inert gas (TIG) welding process. A mathematical modelwas developed to predict the weld tensile test in (1). Weld Tensile test of 596.218 MPa with a desirability value of $95.70 \%$ was observed to be the best, resulting from the optimized process parameters of current of 120.00 Amp, voltage of 20.00 volt and gas flow rate of $12.00 \mathrm{~L} / \mathrm{min}$. This process parameters produced the most reliable weldment on the specimen, with current having the highest effect on the quality of the weldment.

\section{REFERENCES}

[1] Etin-Osa, C.E. Achebo, J. I. and Obahiagbon, K. O. (2020). Design and Fabrication of Portable Weld Residual Stress Measuring Device using MBN Principle. NIPES Journal of Science and Technology Research 2(3), pp. 70-84.

[2] Imhansoloeva N.A, Achebo J.I, Obahiagbon K.O, Osarenmwinda J.O, Etin-Osa C.E. (2018). Optimization of the Deposition Rate of Tungsten Inert Gas Mild Steel Using Response Surface Methodology. Scientific Research Publishing. vol. 10, pp. 784-804.

[3] Achebo, J. and Odinikuku, W. (2015) Optimization of Gas Metal Arc Welding Process parameters using Standard Deviation (SDV) and Multi-Objective Optimization on the Basis of Ratio Analysis (MOORA). Journal of Minerals and Materials Characterization and Engineering. 3. 298-308.

[4] Achebo, J. I. (2011) "Optimization of GMAW Protocols and Parameters for Improving Weld Strength Quality". delivered at the 2011 World Congress on Engineering: International Conference of Manufacturing Engineering and Engineering.

[5] Achebo, J.I. (2012): Complex Behavior of Forces Influencing Molten Weld Metal Flow based on Static Force Balance Theory 2012 International Conference on Solid State Devices and Materials Science Physics Procedia 25 (2012), 317-324.

[6] Etin-osa C.E and Achebo J.I (2017). Analysis of Optimum Butt Welded Joint for Mild Steel Components Using FEM (ANSYS). American Journal of Naval Architecture and Marine Engineering 2017; 2(3): 61 $70 \mathrm{http} / / / \mathrm{www}$. sciencepublishinggroup.com/j/ajname doi: 10.11648/j.ajname.20170203.12.

[7] Kumar, V. (2011). Modeling of Weld Bead Geometry and Shape Relationships in Submerged Arc Welding Using Developed Fluxes. Jordan Journal of Mechanical and Industrial Engineering Vol. 5, No. 5, pp. 461-470. 